\title{
Guidewire-assisted method to achieve hemostasis in colonic diverticular bleeding in the ascending colon
}

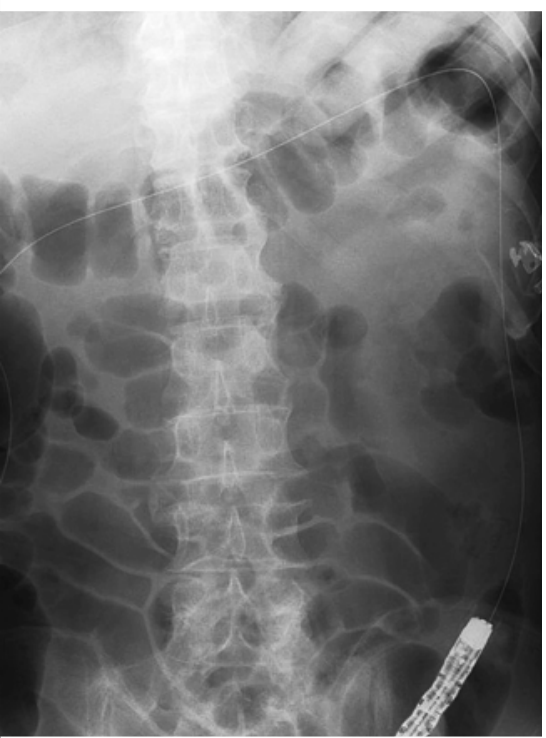

- Fig. 1 Radiographic image showing the guidewire that had been inserted through the forceps hole at the tip of the scope, which we ensured using the imaging remained in the ascending colon as the scope was carefully withdrawn.

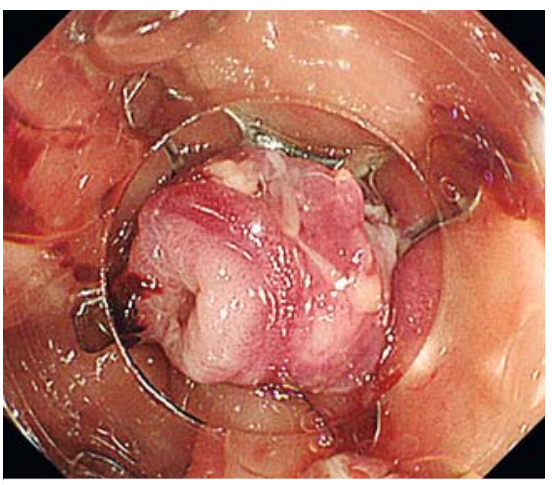

- Fig. 2 Endoscopic image showing the over-the-scope clip applied at the diverticulum and successfully achieving hemostasis.

A 61-year-old man was admitted because of colonic diverticular bleeding. Despite having achieved hemostasis at the cecum using five clips on the second day of admission, he re-bled on the third day, so we again performed a colonoscopy. During this colonoscopy, we removed

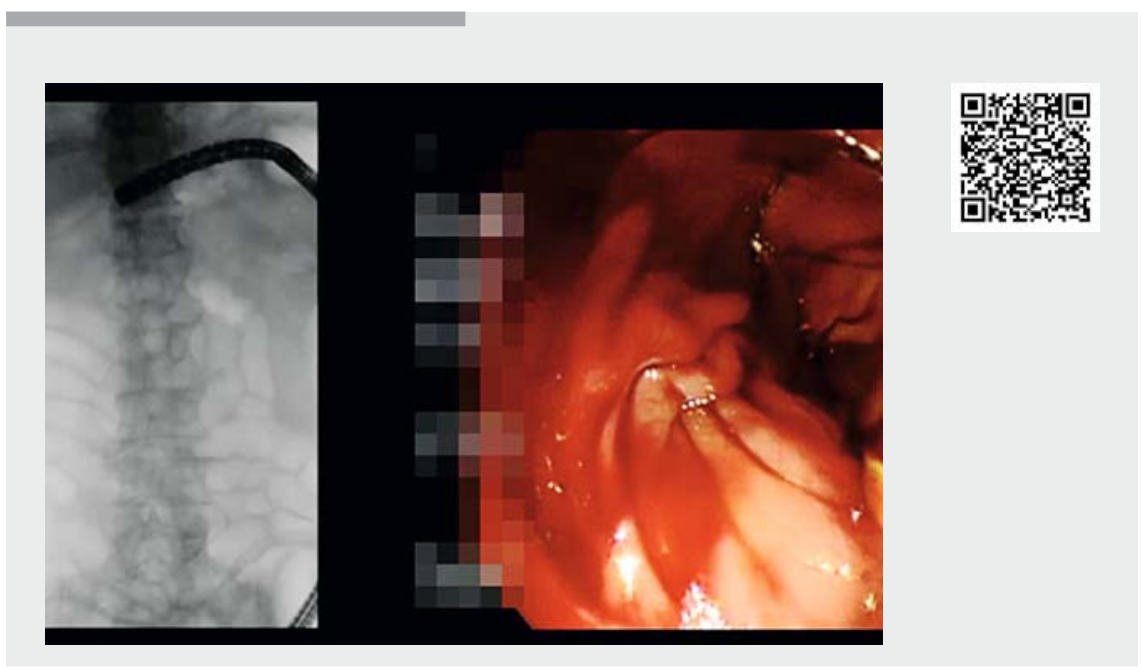

Video 1 Guidewire-assisted method to achieve insertion of an endoscope with an overthe-scope clip attached to its tip into the ascending colon to treat diverticular bleeding.

the previously placed clips and, after placing a 0.035 -inch biliary guidewire and withdrawing the colonoscope ( $\triangleright$ Fig. 1 ), we attached an over-the-scope (OTS) clip (Ovesco Endoscopy AG, Tübingen, Germany) to the tip of the scope. We then re-inserted it into the cecum following the guidewire. Hemostasis was achieved using the OTS clip ( Fig. 2; - Video 1). The patient's condition improved after this intervention, and he was discharged from hospital on the ninth day of admission.

OTS clips have been used for gastrointestinal bleeding, perforations, and fistulas, full-thickness resection of tumors, stent anchoring, and to achieve hemostasis in cases of colonic diverticular bleeding [1-3]. In our case, we successfully used an OTS clip to stop diverticular bleeding after hemostasis by clipping had failed. One shortfall of OTS clips is that they restrict the endoscopic view when attached to the tip of the scope. To overcome this disadvantage, we used a guidewire inserted through the forceps hole at the tip of the scope, before its withdrawal. We withdrew the scope carefully and simultaneously ensured that the guidewire remained in the ascending colon using radiographic imaging. After withdrawing the scope, we attached the OTS clip and re-inserted the scope into the ascending colon following the guidewire, subsequently achieving hemostasis. In this manner, a scope with an OTS clip attached to it can quickly be advanced into the proximal colon, even in patients with heavy bleeding, as in this case.

This method might also be helpful to achieve hemostasis with endoscopic band ligation for diverticular bleeding [4], which also requires a dedicated attachment.

Endoscopy_UCTN_Code_TTT_1AQ_2AZ

\section{Competing interests}

The authors declare that they have no conflict of interest. 
The authors

Eisuke Akamine, Satoshi Asai, Hitomi Jimbo, Kotaro Takeshita, Takumi Ichinona, Naoki Fujimoto

Department of Gastroenterology, Tane General Hospital, Osaka, Japan

\section{Corresponding author}

Eisuke Akamine, MD

Kujyominami 1-12-21, Nishi-Ku, Osaka-City, Osaka, Japan

cyapu2006@yahoo.co.jp

\section{References}

[1] Monkemuller K, Peter S, Toshniwal J et al. Multipurpose use of the 'bear claw' (overthe-scope-clip system) to treat endoluminal gastrointestinal disorders. Dig Endosc 2014; 26: $350-357$
[2] Probst A, Braun G, Golder S et al. Endoscopic treatment of colonic diverticular bleeding using an over-the-scope clip. Endoscopy 2016; 48: E160

[3] Wedi E, von Renteln D, Jung C et al. Treatment of acute colonic diverticular bleeding in high risk patients, using an over-thescope clip: a case series. Endoscopy 2016; 48: E383-E385

[4] Higashi R, Kinugasa H, Nakagawa M. Endoscopic band ligation for colonic diverticular bleeding. Dig Endosc 2018; 30: 399

Bibliography

Endoscopy 2021; 53: E120-E121

DOI 10.1055/a-1216-0413

ISSN 0013-726X

published online 24.7.2020

(c) 2020. Thieme. All rights reserved.

Georg Thieme Verlag KG, Rüdigerstraße 14,

70469 Stuttgart, Germany
ENDOSCOPY E-VIDEOS

https://eref.thieme.de/e-videos

口回 Endoscopy E-Videos is a free 然 access online section, reporting 田: on interesting cases and new

techniques in gastroenterological endoscopy. All papers include a high quality video and all contributions are freely accessible online.

This section has its own submission website at https://mc.manuscriptcentral.com/e-videos 